This item was submitted to Loughborough's Institutional Repository (https://dspace.lboro.ac.uk/) by the author and is made available under the following Creative Commons Licence conditions.

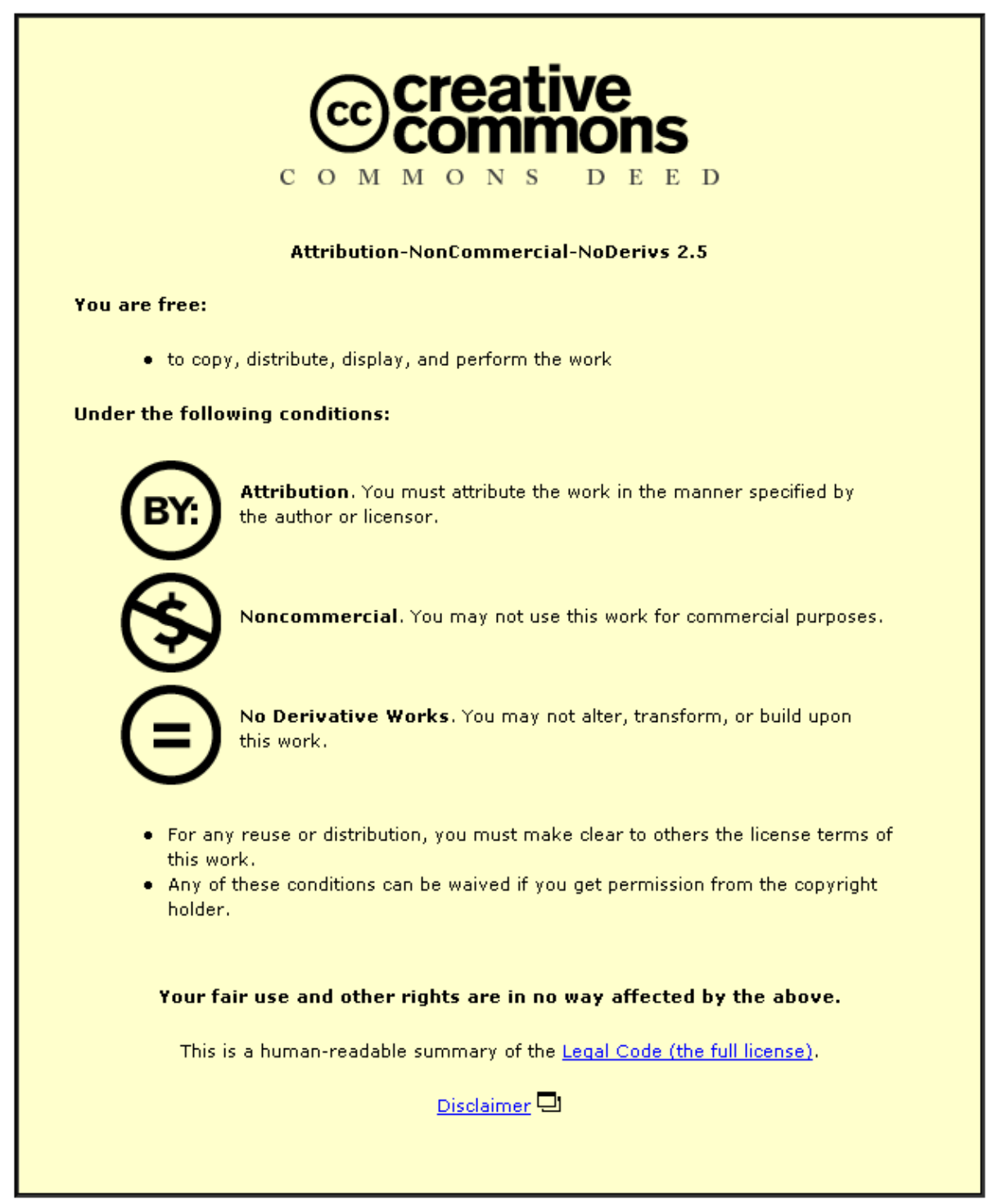

For the full text of this licence, please go to: http://creativecommons.org/licenses/by-nc-nd/2.5/ 


\section{Humidity buffering using stabilised rammed earth materials}

David Allinson MSc, PhD

Senior Research Associate, School of Civil and Building Engineering, Loughborough University, Leicestershire, UK
Matthew Hall BSC, PhD, CSci, CEng, MIMMM, MInstP

Associate Professor in Materials Engineering, Nottingham Centre for

Geomechanics, University of Nottingham, Nottingham, UK

The humidity buffering potential of stabilised rammed earth materials is investigated based on the moisture buffer value concept. The moisture buffer value is (a) measured experimentally, (b) calculated from an analytical solution of the mass transfer and (c) simulated using a numerical solution of the combined heat and mass transfer. The numerical solution to the equations is described, as well as the modelling tool termed 'CHAMP' (coupled heat and mass transport in porous media). The results show that stabilised rammed earth can be a 'good' moisture buffering material under the Nordtest classification scheme. They also show that the moisture buffer value of stabilised rammed earth materials could be optimised or maximised by controlling the grading and mineralogy of the sub-soil and the manufacturing techniques. Sensitivity analysis of the moisture buffer value to the moisture transfer resistance at the surface is explored through numerical simulation and the need to control the experimental measurement carefully is explored.

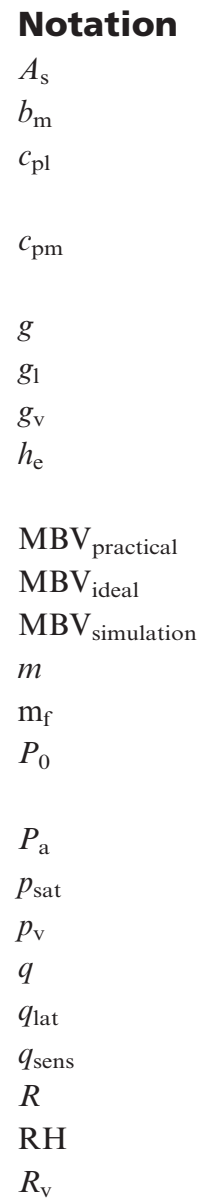

area of surface $\left(\mathrm{m}^{2}\right)$

moisture effusivity $\left(\mathrm{kg} /\left(\mathrm{m}^{2} \mathrm{~Pa} \mathrm{~s}^{1 / 2}\right)\right)$

constant pressure specific heat capacity (water) $(\mathrm{J} / \mathrm{kg} \mathrm{K})$

constant pressure specific heat capacity (dry material) $(\mathrm{J} / \mathrm{kg} \mathrm{K})$

total rate of mass transfer $\left(\mathrm{kg} / \mathrm{s} \mathrm{m}^{2}\right)$ rate of liquid water transfer $\left(\mathrm{kg} / \mathrm{s} \mathrm{m}^{2}\right)$ rate of water vapour transfer $\left(\mathrm{kg} / \mathrm{s} \mathrm{m}^{2}\right)$ specific latent enthalpy of evaporation (or condensation) $(\mathrm{J} / \mathrm{kg})$

measured moisture buffer value $\left(\mathrm{g} / \mathrm{m}^{2} \% \mathrm{RH}\right)$ analytical moisture buffer value $\left(\mathrm{g} / \mathrm{m}^{2} \% \mathrm{RH}\right)$ simulated moisture buffer value $\left(\mathrm{g} / \mathrm{m}^{2} \% \mathrm{RH}\right)$ mass $(\mathrm{g})$

moisture factor for thermal conductivity standard atmospheric pressure (barometric) $(\mathrm{Pa})$

total air pressure $(\mathrm{Pa})$

saturation vapour pressure $(\mathrm{Pa})$ partial pressure of water vapour $(\mathrm{Pa})$ total heat flux $\left(\mathrm{W} / \mathrm{m}^{2}\right)$ latent heat flux $\left(\mathrm{W} / \mathrm{m}^{2}\right)$ sensible heat flux $\left(\mathrm{W} / \mathrm{m}^{2}\right)$ thermal resistance $\left(\mathrm{m}^{2} \mathrm{~K} / \mathrm{W}\right)$ relative humidity $(\%)$ resistance to water vapour transfer $\left(\mathrm{m}^{2}\right.$ s Pa/kgv)

$\begin{array}{ll}R_{\text {vap }} & \begin{array}{l}\text { individual gas constant of water vapour } \\ (\mathrm{J} / \mathrm{kg} \mathrm{K})\end{array} \\ T & \text { thermodynamic temperature }(\mathrm{K}) \\ t & \text { time (s) } \\ t_{\mathrm{p}} & \text { time period (s) } \\ w & \text { specific moisture content }\left(\mathrm{kg} / \mathrm{m}^{3}\right) \\ w_{\mathrm{m}} & \text { moisture content }(\mathrm{kg} / \mathrm{kg}) \\ x & \text { one-dimensional distance }(\mathrm{m}) \\ \delta_{\mathrm{a}} & \text { water vapour permeability of still air } \\ & (\mathrm{kg} / \mathrm{m} \text { s Pa) } \\ \delta_{\mathrm{p}} & \text { water vapour permeability }(\mathrm{kg} / \mathrm{m} \mathrm{s} \mathrm{Pa)} \\ \lambda^{*} & \text { moisture-dependent thermal conductivity } \\ & \text { (W/m K) } \\ \mu & \text { water vapour diffusion resistance factor } \\ \xi & \text { moisture capacity (kg/kg) } \\ \rho_{\mathrm{d}} & \text { dry density }\left(\mathrm{kg} / \mathrm{m}^{3}\right) \\ \varphi & \text { relative humidity (decimal) }\end{array}$

\section{Introduction}

Humidity buffering occurs when porous building materials modify the relative humidity of indoor air, through absorption, storage and desorption of water vapour. This reduces the magnitude of relative humidity fluctuations in the same way that thermal mass reduces temperature swings. Excess water vapour inside buildings can originate from the occupants themselves (e.g. respiration and perspiration) and from their activities (e.g. cooking and washing). Buildings are traditionally designed so that this moisture can be removed by natural or mechanical 
ventilation. Significantly, the desire to improve the energy efficiency of buildings may lead to a reduction in the ventilation rate in some cases and many building materials are finished with vapour-resistant coatings (e.g. paint and vinyl wallpaper), which can lead to problems with moisture accumulation (Oreszczyn et al., 2006). Equally, the heating and/or air conditioning of buildings can produce problematic low-humidity indoor environments. Carefully selected, humidity buffering building materials could be used to even out these daily or seasonal variations.

Research into humidity buffering materials has been motivated by a number of factors: the thermal comfort of building occupants is closely related to the humidity of the indoor air (Fang et al., 1998a, 1998b; Kurnitski et al., 2007; Simonson et al., 2002); certain environments require tight humidity control to prevent damage to their contents (e.g. historic buildings, museums and art galleries) (Padfield, 1998); excessive humidity can promote dust mite populations and the growth of unsightly mould, both of which are known to be allergens with potentially serious health effects (Howieson, 2003; Oreszczyn et al. 2006); condensation and damp can significantly reduce the life of building materials; and finally, passive control of humidity by the fabric of the building may reduce or even remove the need for mechanical air conditioning, reducing the amount of energy required (Osanyintola and Simonson, 2006) as well as the running cost of the building. The moisture buffer value $(\mathrm{MBV})$ is a single parameter that can be used to describe and compare the humidity buffering potential of building materials (Rode, 2005).

Stabilised rammed earth (SRE) is a traditional building technique in which moistened sub-soil material is dynamically compacted into formwork to create monolithic wall structures. Stabilisation, to improve durability and strength, is achieved through modification of the soil properties. Typically, in modern practice, this entails the addition of Portland cement in quantities up to $10 \%$ by mass. The technique is well established and used around the world and it may be considered a sustainable material with low embodied energy, especially when the sub-soil is sourced locally (Mendonca, 2007). SRE is also known (anecdotally) for its passive air-conditioning ability, that is the occupants of SRE buildings enjoy improved thermal comfort through the passive moderation of indoor temperature and humidity fluctuations (Minke, 2000; Mortenson, 2000; Taylor and Luther 2004). These abilities can perhaps be attributed to the combined effects of the thermal mass (air temperature buffering) of the material and its humidity buffering potential.

Quantifying the speculated humidity buffering potential of SRE is the subject of this paper. The MBV of three contrasting SRE materials, with a range of hygrothermal functional properties, was determined by experiment, analytical calculation and numerical simulation. The results were compared with other building materials. The numerical model, developed by the authors for this study, was used to explore the sensitivity of the results to variations in surface moisture transfer resistance. In this way, the paper demonstrates different methodologies that can be used to assess the moisture buffering ability of any porous building materials. It also quantifies the largely qualitative assessment that SRE is a good humidity buffering material.

\section{Stabilised rammed earth materials and sample preparation}

Stabilised rammed earth materials demonstrate a wide range of material properties that depend on the type of soil used (mineralogy and particle size distribution), the type and amount of binder, the energy used in compaction and the moisture content at compaction. Three different SRE materials, named after the mass proportions of a sand, a gravel and a silty clay that were combined to make the samples, were used for this investigation: 613, 433 and 703. Therefore, 613 SRE was manufactured from a mix of $60 \%$ sand, $10 \%$ gravel and $30 \%$ silty clay, by dry mass. The sand, gravel and silty clay were sourced from quarries located in the same geological area. Further characteristics and physical properties of these SRE mix designs can be found elsewhere (Hall and Djerbib, 2004).

The SRE samples used for the MBV tests were 'disc type' with dia. $105 \mathrm{~mm}$ and approximately $40 \mathrm{~mm}$ high. All were compacted using the same compaction energy and at the optimal moisture content, which was determined as $8 \%$ wt by BS 1377-4:1990 Proctor light (BSI, 1990). They were cured for a minimum of 28 days at $20^{\circ} \mathrm{C}$ and $75 \%$ relative humidity. In this way reproducible samples of different SRE materials could be manufactured. This provided a range of physical structures (density, porosity and void size distribution) which resulted in a range of hygrothermal functional properties: moisturedependent thermal conductivity; moisture-dependent volumetric heat capacity; moisture storage function (sorption/ desorption isotherms); and liquid and vapour permeability coefficients. The measurement of these properties has been described elsewhere (Hall and Allinson, 2009) and the results are summarised in Table 1.

\section{Experimental measurement of MBV}

The MBV of the SRE materials was measured after the Nordtest technique (Rode, 2005). This involved measuring the change in mass that resulted from repeatedly exposing one surface of the samples to $8 \mathrm{~h}$ in a high-humidity environment (nominally $75 \%$ $\mathrm{RH}$ ) followed by $16 \mathrm{~h}$ in a low humidity (nominally $33 \% \mathrm{RH}$ ) under constant temperature (nominally $23^{\circ} \mathrm{C} \pm 2$ ) conditions. This was achieved using two small climate boxes that contained saturated solutions of sodium chloride $(\mathrm{NaCl})$ and magnesium chloride $\left(\mathrm{MgCl}_{2}\right)$ to provide the specified humidity steps of $75 \%$ and $33 \%$, respectively. They were located in a larger (walk-in) 


\begin{tabular}{|c|c|c|c|c|c|c|}
\hline Material & $\begin{array}{c}\text { Density, } \rho_{\mathrm{d}} \text { : } \\
\mathrm{kg} / \mathrm{m}^{3}\end{array}$ & $\begin{array}{l}\text { Heat capacity: } \\
C_{\mathrm{pm}}: \mathrm{J} / \mathrm{kg} \mathrm{K}\end{array}$ & $\begin{array}{c}\text { Thermal } \\
\text { conductivity, } \lambda \text { : } \\
\text { W/m K }\end{array}$ & $\begin{array}{l}\text { Moisture } \\
\text { factor, } m_{\mathrm{f}}\end{array}$ & $\begin{array}{l}\text { Moisture } \\
\text { capacity, } \xi \text { : } \\
\text { kg/kg }\end{array}$ & $\begin{array}{c}\text { Water vapour } \\
\text { permeability, } \delta_{\mathrm{p}} \text { : } \\
\text { kg/m s Pa }\end{array}$ \\
\hline 613 SRE & 2020 & $868 \cdot 3$ & $0 \cdot 83$ & $0 \cdot 00245$ & $0 \cdot 01186$ & $1.27 \times 10^{-11}$ \\
\hline 433 SRE & 2120 & $868 \cdot 3$ & $1 \cdot 01$ & 0.0034 & 0.01292 & $5 \cdot 75 \times 10^{-12}$ \\
\hline 703 SRE & 1980 & $868 \cdot 3$ & 0.87 & 0.00322 & 0.00890 & $1.88 \times 10^{-11}$ \\
\hline Gypsum board & $1000^{a}$ & $840^{b}$ & $0 \cdot 16^{b}$ & 0 & 0.03100 & $2.50 \times 10^{-11 a}$ \\
\hline Brick & $1600^{a}$ & $800^{b}$ & $0.62^{b}$ & 0 & 0.00240 & $3.00 \times 10^{-11 a}$ \\
\hline Spruce boards & $430^{a}$ & $2300^{b}$ & $0 \cdot 12^{b}$ & 0 & $0 \cdot 19005$ & $1.50 \times 10^{-12 a}$ \\
\hline
\end{tabular}

a Values from Nordtest (Rode, 2005).

bValues from CIBSE Guide A (CIBSE, 2006).

Table 1. Functional properties of the materials

insulated chamber that was maintained at $23^{\circ} \mathrm{C}$ by a thermostatic controller, an electrical natural convection heater and a fan. The SRE test sample was placed on an electronic balance (accuracy $\pm 0.01 \mathrm{~g}$ ) that was incorporated under a special lid so that it could be placed in each of the climate boxes in turn. The sides and base of the specimens were sealed with a combination of a two-part epoxy resin adhesive and aluminium tape. A low-voltage fan was incorporated into the lid to ensure a steady air flow over the specimen surface and a 'Tinytag' data logger (accuracy: $\pm 0 \cdot 5^{\circ} \mathrm{C} \pm 2 \% \mathrm{RH}$ ) recorded temperature and relative humidity at $10 \mathrm{~min}$ intervals. The output from the balance was recorded every minute by way of an RS232 cable attached to a personal computer (PC). A schematic diagram of the test set-up is shown in Figure 1. The specimens were conditioned at $23^{\circ} \mathrm{C}$ and $50 \% \mathrm{RH}$ before the test. The test duration depended upon the required equilibration period and was typically 5 days.
The MBV ( $\mathrm{MBV}_{\text {practical }}$ ) was calculated from the average of the mass gained by the sample during absorption (in 75\% $\mathrm{RH}$ climate) and the mass lost during the subsequent desorption phase (33\% RH climate), as shown in Figure 2. This change in mass was divided by the exposed area of the sample and the difference in relative humidity between the two environments, as shown in Equation 1. The quoted values of $\mathrm{MBV}_{\text {practical }}$ were the average of three consecutive results

1. $\mathrm{MBV}_{\text {practical }}=\frac{\Delta m}{A_{\mathrm{s}} \Delta \mathrm{RH}}$

A limitation of the technique was that the climate did not respond quickly to the sudden variations in relative humidity that occurred when the specimen was transferred from one environment to the other. Figure 3 shows the recorded

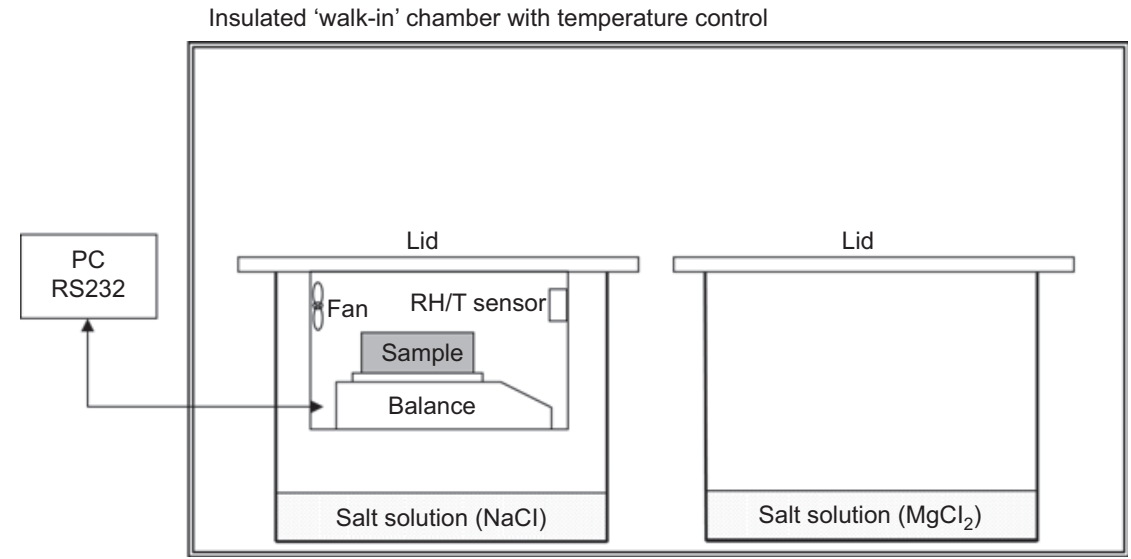

Figure 1. Schematic diagram of the MBV measurement set-up 


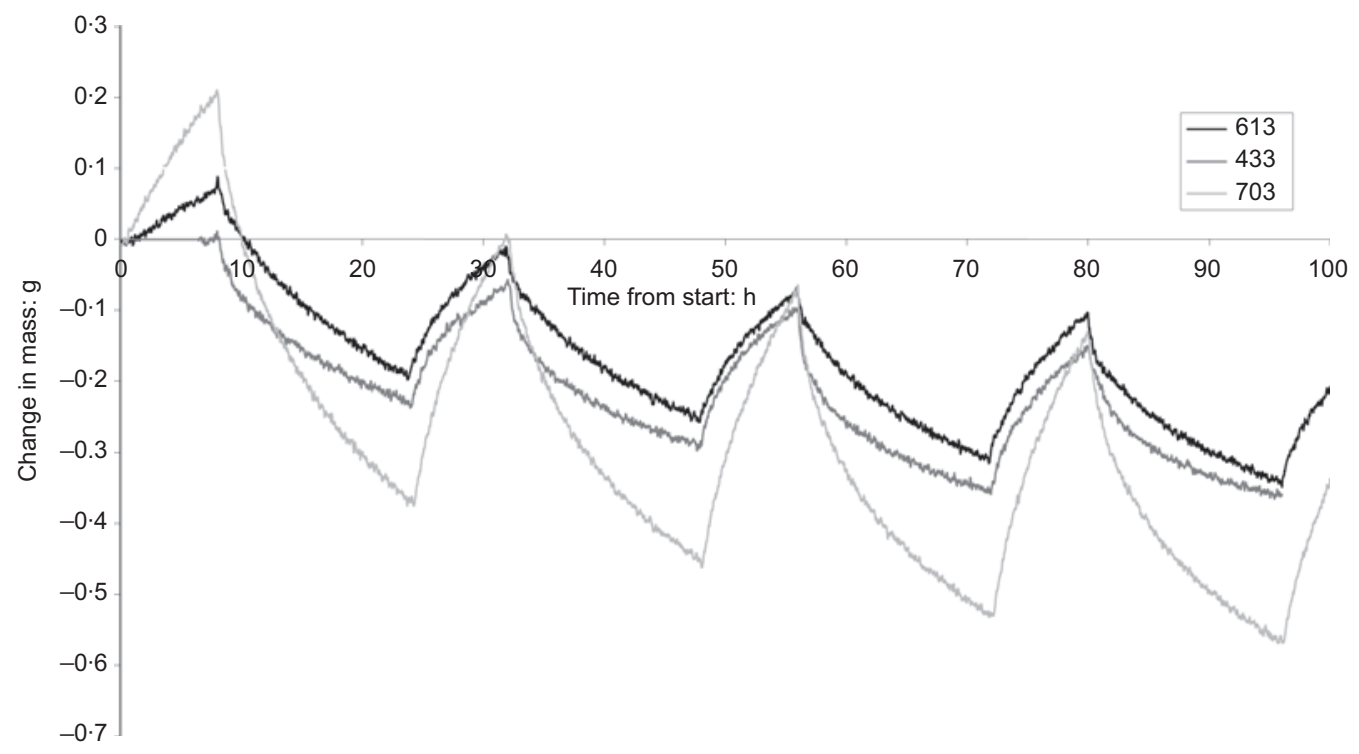

Figure 2. Recorded mass-time profiles for the MBV measurement

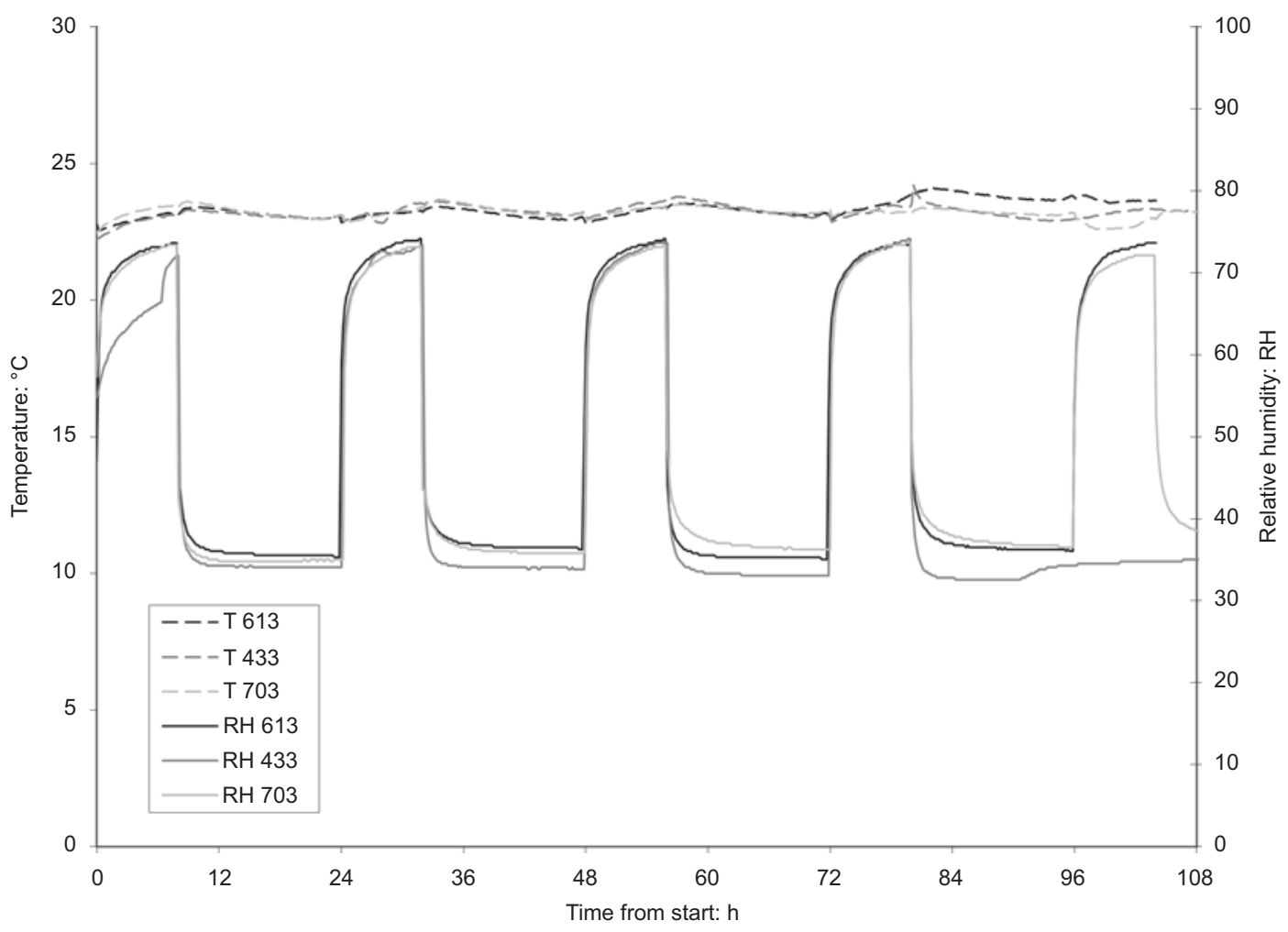

Figure 3. Recorded relative humidity and temperature profiles for the MBV measurement 
temperature and relative humidity: the air temperature remained stable and the relative humidity, although slow to respond to each step change, achieved acceptable values in relation to the target set point. The maximum and minimum achieved values of relative humidity were used in the calculation of $\mathrm{MBV}_{\text {practical, }}$ although it should be recognised that specimens were never exposed to these relative humidity values for the full duration of each time step. In this way the calculated $\mathrm{MBV}_{\text {practical }}$ values are likely to be conservative.

The repeatability of the MBV measurement has been explored in previous research by inter-laboratory round robin testing which showed that results varied by up to about $20 \%$ (Rode, 2005). This may be due (at least in part) to the sensitivity of the result to the near-surface air film resistance and the difficulty in controlling the air flow over the specimen; an issue which is explored later in this paper.

\section{Analytical calculation of MBV}

An analytical method for calculating the MBV from standard material properties was defined by the Nordtest project (Rode, 2005) as shown in Equation 2

\section{2. $\mathrm{MBV}_{\text {ideal }}=0 \cdot 00568 p_{\mathrm{s}} b_{\mathrm{m}} \sqrt{t_{\mathrm{p}}}$}

The value of the material effusivity is calculated by Equation 3

3. $b_{\mathrm{m}}=\sqrt{\frac{\delta_{\mathrm{p}} \rho_{\mathrm{d}}\left(\partial w_{\mathrm{m}} / \partial \varphi\right)}{p_{\mathrm{sat}}}}$

For the SRE materials, a single value of $\partial w_{\mathrm{m}} / \partial \varphi$ was calculated from the gradient of the straight line portion of the measured moisture storage function for each material (moisture capacity, $\xi$ (see Hall and Allinson (2009) for more details).

Equations 2 and 3 result from an analytical solution of the mass transport between the test specimen and the air, and assume no boundary layer resistance. For this reason it is referred to as the 'ideal moisture buffer value' or $\mathrm{MBV}_{\text {ideal }}$ and is the maximum possible value of the MBV. The results for the $\mathrm{MBV}_{\text {ideal }}$ for each of the three SRE material types are presented in Table 2.

Where there is little air movement over the material's surface, the still boundary layer of air will increase surface moisture transfer resistance and the MBV will be lower than suggested by the analytical solution. To explore the relationship between the MBV and surface moisture transfer resistance, a numerical solution was developed.

\begin{tabular}{lccc} 
Material & $\begin{array}{r}\mathrm{MBV}_{\text {practical }}: \\
\mathrm{g} / \mathrm{m}^{2} \% \mathrm{RH}\end{array}$ & $\begin{array}{c}\mathrm{MBV}_{\text {ideal }}: \\
\mathrm{g} / \mathrm{m}^{2} \% \mathrm{RH}\end{array}$ & $\begin{array}{c}\mathrm{MBV}_{\text {simulation: }} \\
\mathrm{g} / \mathrm{m}^{2} \% \mathrm{RH}\end{array}$ \\
\hline 613 & 0.68 & 1.54 & 1.35 \\
433 & 0.61 & 1.11 & 1.00 \\
703 & 1.29 & 1.61 & 1.43 \\
Gypsum board & $0.64^{\mathrm{a}}$ & 2.46 & 1.88 \\
Brick & $0.48^{\mathrm{a}}$ & 0.95 & 0.71 \\
Spruce boards & $1.16^{\mathrm{a}}$ & $3 \cdot 10$ & $2 \cdot 20$ \\
\hline
\end{tabular}

aValues from Nordtest (Rode, 2005)

Table 2. Summary of MBV

\section{Numerical simulation of MBV}

Combined heat and mass transfer equations, suitable for a numerical solution, are outlined in BS EN 15026:2007 (BSI, 2007). For this paper, a numerical solution of those equations was developed in the MathWorks Matlab high-level language. The program was named 'CHAMP' (for 'combined heat and mass in porous' materials). It utilised a time-marching, explicit finite-volume method to solve the discretised partial differential equations.

The total rate of heat transfer is considered to be the sum of the sensible and latent (due to vapour diffusion) heat transfer rates

4. $q=q_{\text {sens }}+q_{\text {lat }}$

The rate of sensible heat transfer is calculated using Fourier's law of heat conduction, where the thermal conductivity is a function of the moisture content and temperature increases with distance

5. $q_{\mathrm{sens}}=-\lambda^{*} \frac{\partial T}{\partial x}$

The rate of latent heat transfer within the material and across boundaries is calculated from the rate of water vapour transfer and the specific latent enthalpy of evaporation (or condensation)

6. $q_{\text {lat }}=h_{\mathrm{e}} g_{\mathrm{v}}$

The value of enthalpy $\left(2.45 \times 10^{6} \mathrm{~J} / \mathrm{kg}\right)$ was assumed to be the same for both evaporation and condensation.

The total rate of mass transfer is calculated from the sum of the rates of water vapour and liquid water transfer 


\section{7. $g=g_{\mathrm{v}}+g_{1}$}

The rate of water vapour transfer in the porous material is described by

8. $g_{\mathrm{v}}=-\delta_{\mathrm{p}} \frac{\partial p_{\mathrm{v}}}{\partial x}$

The partial pressure of water vapour was calculated from the relative humidity (from the moisture storage function) using the relationship

9. $\quad p_{\mathrm{v}}=\phi 610 \cdot 5 \mathrm{e}^{\frac{17 \cdot 269(T-273 \cdot 15)}{T-35 \cdot 85}}$

The experimentally measured water vapour diffusion resistance factor was used to describe the vapour permeability of the material in terms of the vapour permeability of still air at the same temperature and pressure

10. $\delta_{\mathrm{p}}=\frac{\delta_{\mathrm{a}}}{\mu}$

The vapour permeability of still air was calculated from the Schirmer formula

11. $\delta_{\mathrm{a}}=\frac{2 \cdot 306 \times 10^{-5}}{R_{\text {vap }} T} \frac{P_{0}}{P_{\mathrm{a}}}\left(\frac{T}{273 \cdot 15}\right)^{1 \cdot 81}$

The ratio of the standard atmospheric pressure (101 $325 \mathrm{~Pa})$ to the actual barometric pressure was assumed to be unity. Liquid moisture transfer was set to zero because the maximum relative humidity was $75 \%$ for the duration of the tests and hence mass transport would be governed by diffusion as opposed to capillary potential.

In order to simulate the time-varying one-dimensional hygrothermal behaviours, the heat and mass transfer equations described above were combined using balancing equations derived from the conservation of energy and conservation of mass. Considering an elemental control volume of a porous building material, as shown in Figure 4, by conservation of heat energy, the rate of accumulated heat is a result of the net rate of heat transfer into that volume

12. $\left(\rho_{\mathrm{d}} c_{\mathrm{pm}}+w c_{\mathrm{pl}}\right) \frac{\partial T}{\partial t}=-\frac{\partial q}{\partial x}$

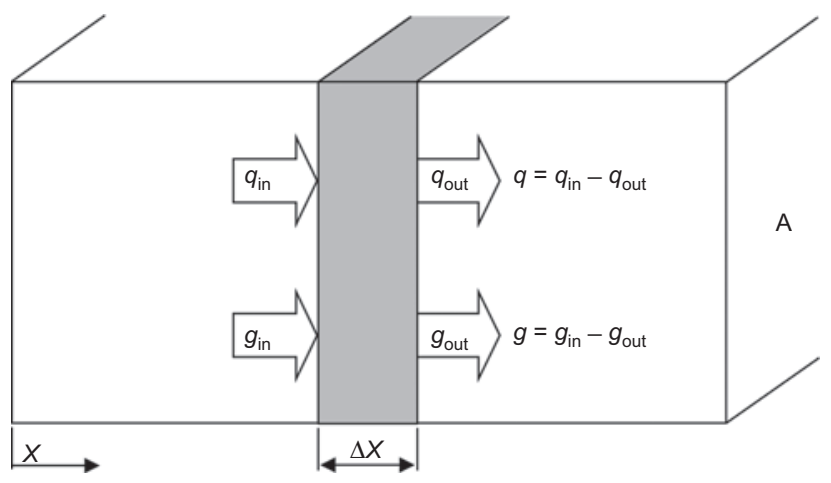

Figure 4. Simulated control volume in cross-section of wall

Similarly, by conservation of mass, the rate of accumulated moisture is a result of the net inflow rate of moisture

13. $\frac{\partial w}{\partial t}=-\frac{\partial g}{\partial x}$

The negative symbol on the right-hand side of each equation indicates that both heat and moisture will flow from areas of high potential to areas of lower potential. Each of these equations must be satisfied at every position within the material and at any time.

To solve the simultaneous partial differential equations described above, a numerical solution was used that divided the wall into discrete elements that could then be studied at discrete time steps. The schematic diagram in Figure 5 shows a notional building wall divided into a number of control volumes. The heat (energy) and moisture (mass) for each control volume were assumed to be stored at the central node. The resistance to the flow of heat between any two adjacent

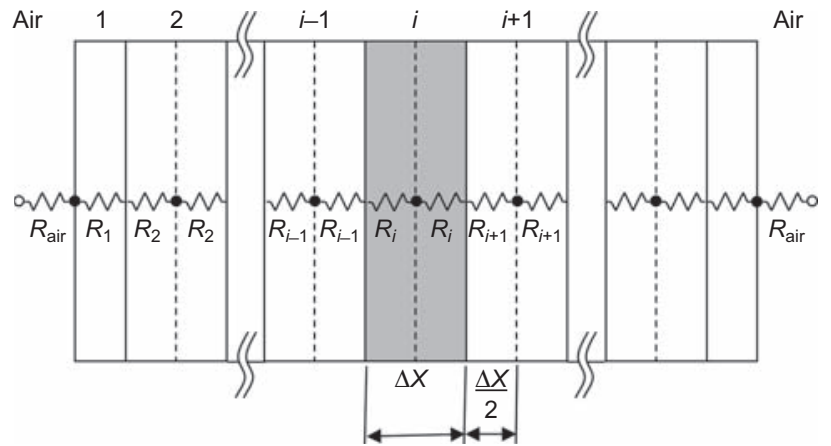

Figure 5. Simulated control volume resistances for finite-volume analysis 
nodes was described, using an electrical analogy, by two thermal resistors connected in series (see Figure 5). Each resistor represented half of the control volume such that

14. $R=\frac{\Delta x / 2}{\lambda^{*}}$

By assuming small values of $\Delta x$ such that $\Delta x \rightarrow \partial x$ and $\Delta T \rightarrow \partial T$ the resistances were substituted into the transport equation (Equation 5), to give the rate of sensible heat transfer for the $i$ th control volume from its neighbouring volumes, subscripted $i-1$ and $i+1$

15. $q_{\mathrm{sens}, i}=\frac{T_{i-1}-T_{i}}{R_{i-1}+R_{i}}+\frac{T_{i+1}-T_{i}}{R_{i+1}+R_{i}}$

Similarly, the resistance to the flow of water vapour between each node and the edge of its control volume was calculated from the vapour permeability

16. $R_{\mathrm{v}}=\frac{\Delta x / 2}{\delta_{\mathrm{p}}}$

Substituting these resistance values into their transport equation (Equation 8), gave the rates of water vapour transfer for the $i$ th control volume

17. $g_{\mathrm{v}, i}=\frac{p_{\mathrm{v}, i-1}-p_{\mathrm{v}, i}}{R_{\mathrm{v}, i-1}+R_{\mathrm{v}, i}}+\frac{p_{\mathrm{v}, i+1}-p_{\mathrm{v}, i}}{R_{\mathrm{v}, i+1}+R_{\mathrm{v}, i}}$

The rate of latent heat transfer was then calculated from the water vapour flow (Equation 6)

18. $q_{\mathrm{lat}, i}=h_{\mathrm{e}} g_{\mathrm{v}, i}$

By inserting these results into the heat and mass balances (Equations 12 and 13) and assuming small values of time step, $\Delta t$ (s), such that $\Delta t \rightarrow \partial t$, these equations were written in a discrete form suitable for numerical analysis as follows

19. $\left(\rho c_{\mathrm{pm}}+w_{i}^{n} c_{\mathrm{pl}}\right) \frac{T_{i}^{n+1}-T_{i}^{n}}{\Delta t}=\left[\frac{q_{\mathrm{sens}, i}+q_{\mathrm{lat}, i}}{\Delta x}\right]^{n}$

20. $\frac{w_{i}^{n+1}-w_{i}^{n}}{\Delta t}=\left[\frac{g_{\mathrm{v}, i}}{\Delta x}\right]^{n}$
In this way, the temperature and moisture content of the $i$ th control volume were calculated at the next time increment, $t+\Delta t$ (parameters superscripted, $n+1$ ) from the current temperature and moisture content and the induced heat and mass transfer (parameters superscripted, $n$ ). The computational algorithm used for the analysis is shown in Figure 6. The computer code was tested and successfully validated to the benchmark example in BS EN 15026:2007 (BSI, 2007), and the results were well within the specified accuracy limits $( \pm 2 \cdot 5 \%)$.

For the simulation of the MBV test, initial conditions were assumed to be $23{ }^{\circ} \mathrm{C}$ and $53 \% \mathrm{RH}$. At time $t=0$ the outside climate was adjusted to $75 \% \mathrm{RH}$ and then $33 \% \mathrm{RH}$ after $8 \mathrm{~h}$. This was repeated on a $24 \mathrm{~h}$ cycle for 5 days. The $40 \mathrm{~mm}$ samples were divided into 101 control volumes. The first and last volume had half of the thickness of those within the wall and the node was located at the surface. Boundary conditions were introduced at both of the outside surfaces. For the first control volume (subscripted ' 1 ') the rate of water vapour diffusion depended upon the partial vapour pressure of the air (subscripted 'air') and its vapour resistance as well as those of the control volume and its neighbour (subscripted ' 2 ') such that

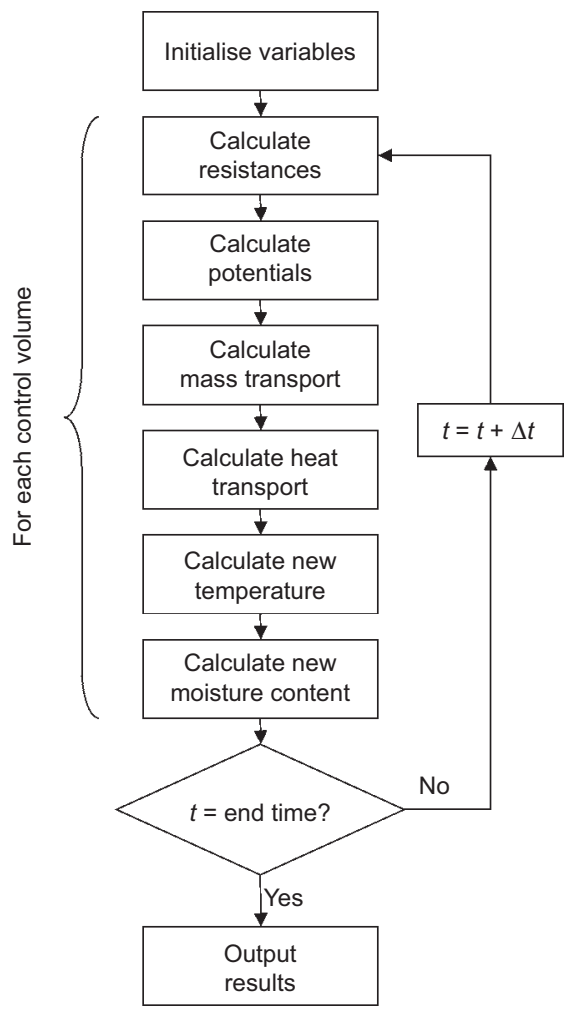

Figure 6. Flow chart of the computational algorithm 
Construction Materials

Volume 165 Issue CM6
Humidity buffering using

stabilised rammed earth

materials

Allinson and Hall
21. $g_{\mathrm{v}, 1}=\frac{p_{\mathrm{v}, \text { air }}-p_{\mathrm{v}, 1}}{R_{\mathrm{v}, \text { air }}}+\frac{p_{\mathrm{v}, 2}-p_{\mathrm{v}, 1}}{R_{\mathrm{v}, 2}+R_{\mathrm{v}, 1}}$

Similarly, the rate of sensible heat transfer for the first control volume was calculated from the air temperature and the surface resistance

22. $q_{\mathrm{sens}, 1}=\frac{T_{\mathrm{air}}-T_{1}}{R_{\mathrm{air}}}+\frac{T_{2}-T_{1}}{R_{2}+R_{1}}$

The rate of latent heat transfer was calculated from the water vapour flow in the usual way

23. $q_{\text {lat }, 1}=h_{\mathrm{e}} g_{\mathrm{v}, 1}$

It was assumed that there was no heat or mass transfer for the last control volume as the samples were sealed on all but one surface. The surface resistances for convective heat transfer and moisture transfer were assumed to be $0.125 \mathrm{~m}^{2} \mathrm{~K} / \mathrm{W}$ and $5 \times 10^{7} \mathrm{~m}^{2} \mathrm{~s} \mathrm{~Pa} / \mathrm{kg}$ respectively, representing indoor surfaces and in agreement with the figures given by Nordtest. MBV values $\left(\mathrm{MBV}_{\text {simulation }}\right)$ were calculated from the resulting masstime profiles in the same way as for the experimental tests and are presented in Table 2.

\section{Results and discussion}

Published results of $\mathrm{MBV}_{\text {practical }}$ for gypsum board, brick and spruce timber boards (Rode, 2005) are included in Table 2 as well as values of $\mathrm{MBV}_{\text {ideal }}$ and $\mathrm{MBV}_{\text {simulation that were }}$ calculated from available published material properties (see Table 1 for values and source). This enabled direct comparison with the three SRE material types studied here.

The results demonstrate that SRE can have a wide range of MBV values, between moderate and good (moderate: $0 \cdot 5-1 \cdot 0 \mathrm{~g} / \mathrm{m}^{2} \% \mathrm{RH}$; good: $1 \cdot 0-2 \cdot 0 \mathrm{~g} / \mathrm{m}^{2} \% \mathrm{RH}$ (Rode, 2005)). In this way, the authors suggest it would be possible to design the behaviour of the SRE walls intelligently to match the moisture fluxes that occur in a particular room and/or for a particular indoor climate or user pattern, chiefly by controlling PSD, mineralogy selection and compaction energy. This hypothesis also reinforces previous findings by the authors (Allinson and Hall, 2010). The results also support the anecdotal evidence that SRE walls do provide good levels of building integrated passive air conditioning. As the three SRE materials tested are not exhaustively representative, it is expected that further control of the grading, mineralogy and manufacturing of the material will lead to a much wider range of $\mathrm{MBV}_{\text {practical }}$ values. An additional advantage of SRE materials is that it is usual to leave their surface exposed to the indoor air, unlike concrete, brick, plaster and timber which are all traditionally covered, painted or varnished; reducing vapour permeability and their effectiveness. The geometry of any exposed material (surface area and material thickness), as well as the temperature profile in the room, would also have to be considered in any analysis to optimise thermal and humidity buffering.

It can be seen from Table 2 that $\mathrm{MBV}_{\text {ideal }}>\mathrm{MBV}_{\text {simulation }}>$ $\mathrm{MBV}_{\text {practical }}$, in all cases. To explore the uncertain relationship between the values, the MBV was simulated for each of the materials at a number of different surface moisture transfer resistances, as shown in Figure 7. It can be seen from the figure that the simulated moisture buffer value $\left(\mathrm{MBV}_{\text {simulation }}\right)$ decreased with increasing surface resistance and that the maximum value (when surface resistance $=0$ ) was the same as the analytical result $\left(\mathrm{MBV}_{\text {ideal }}\right)$. As surface resistance increased, the rate of decrease in the simulated MBV was higher for materials with a higher MBV, until the results for all materials tend towards a similar value, below $0.5 \mathrm{~g} / \mathrm{m}^{20} \% \mathrm{RH}$. A useful indicator of this sensitivity is the moisture Biot number, being the ratio of the moisture resistance of the material to that of the surface film, as described in Nordtest (Rode, 2005).

The MBV was measured at a surface resistance of $(5 \times$ $10^{7} \mathrm{~m}^{2} \mathrm{~s} \mathrm{~Pa} / \mathrm{kg}$ ), as indicated by the grey line on the graph in Figure 7. The uncertainty in the surface moisture transfer resistance in experimental testing will have a greater impact on the uncertainty of the measured MBV values for materials with a higher MBV. However, the variation between the measured and simulated values cannot be simply explained by the uncertainty in the surface resistance. Additional measurement uncertainty will affect both the measured result and the values of the functional properties that are used in the analytical and numerical solutions. This is further compounded by the heterogeneity of construction materials and any variations between samples. These results suggest that careful experimental control and averaging of the results from tests on large numbers of samples would be needed to improve confidence.

As hardened cement paste typically contains meso-pores $(2-50 \mathrm{~nm})$ and some macro-pores $(>50 \mathrm{~nm})$, these additional pores will not have a significant effect on Fickian vapour diffusion but the increased volume of hydrated cement paste could produce a slight pore blocking effect. Since the samples were a minimum of 28 days old at the time of testing, additional hydration caused by vapour absorption is less likely to affect transport behaviour than in early age samples and any changes in pore structure would most likely be restricted near to the surface $(<10 \mathrm{~mm}$ depth). Further study would be required in order to characterise the extent of such microstructural alterations. 


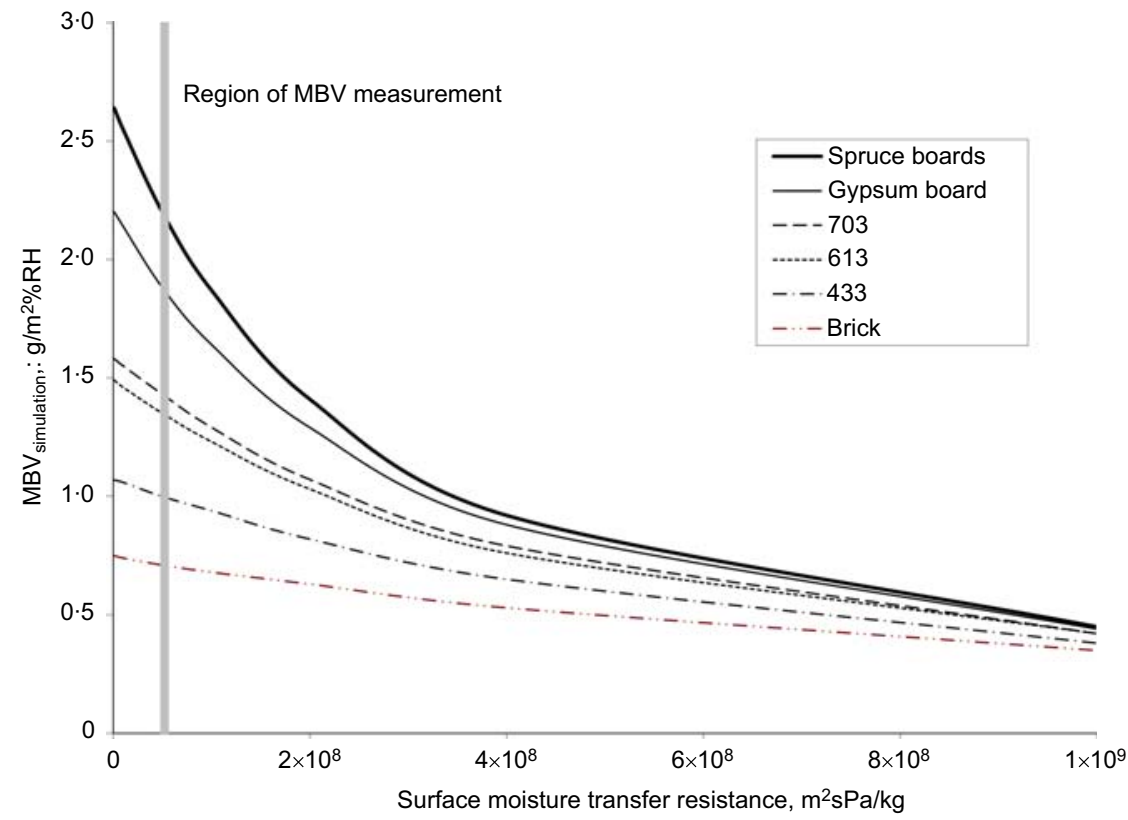

Figure 7. Simulated variation in MBV with surface moisture transfer resistance

\section{Conclusion and future work}

The results of measuring the MBV of three representative SRE material types indicate that SRE can be a good moisture buffering material. Variations in the result between the three mix designs indicate that there is scope for designing the SRE material to maximise its passive air-conditioning potential in a given space. A validated numerical solution (i.e. CHAMP) of the combined heat and mass transfer equations, using a timemarching, explicit, finite-volume method to solve the discretised partial differential equations has been developed. Analysis using this model indicated that materials with higher MBV show a greater decrease in MBV with increasing surface moisture transfer resistance.

Further work is needed to improve the reliability of the MBV measurements by carefully controlling the experimental conditions. These experimental results can then be used as further validation of hygrothermal simulations. The relationship between the grading, mineralogy and manufacturing of SRE materials, and how these relate to material functional properties, determines how the MBV might be optimised to suit a particular application and also the origins of their hygrothermal functional properties. Ultimately, the use of SRE walls to control relative humidity and condensation in buildings could improve occupants' thermal comfort, prevent damage to contents and fabric, improve indoor air quality and save energy.

\section{Acknowledgements}

The authors wish to acknowledge the support of the Engineering and Physical Sciences Research Council for the research presented in this paper (EP/E025684/1).

\section{REFERENCES}

Allinson D and Hall M (2010) Hygrothermal analysis of a stabilised rammed earth test building in the UK. Energy and Buildings 42(6): 845-852.

BSI (1990) BS EN 1377-4: Methods of test for soils for civil engineering purposes. Compaction-related tests. BSI, London, UK.

BSI (2007) BS EN 15026: Hygrothermal performance of building components and building elements - assessment of moisture transfer by numerical simulation. BSI, London, UK.

CIBSE (Chartered Institute of Building Service Engineers) (2006) CIBSE Guide A: Design Data. Chartered Institute of Building Service Engineers, London, UK.

Fang L, Clausen G and Fanger PO (1998a) Impact of Temperature and humidity on perception of indoor air quality during immediate and longer whole-body exposures. Indoor Air 8(4): 276-284.

Fang L, Clausen G and Fanger PO (1998b) Impact of temperature and humidity on the perception of indoor air quality. Indoor Air 8(2): 80-90.

Hall M and Allinson D (2009) Analysis of the hygrothermal 
functional properties of stabilised rammed earth materials. Building and Environment 44(9): 1935-1942.

Hall M and Djerbib Y (2004) Rammed earth sample production: context, recommendations and consistency. Construction and Building Materials 18(4): 281-286.

Howieson SG, Lawson A, Mcsharry C et al. (2003) Domestic ventilation rates, indoor humidity and dust mite allergens: are our homes causing an asthma pandemic. Building Services Engineering Research and Technology 24(3): 137147.

Kurnitski J, Kalamees T, Palonen J, Eskola L and Seppanen O (2007) Potential effects of permeable and hygroscopic lightweight structures on thermal comfort and perceived IAQ in a cold climate. Indoor Air 17(1): 37-49.

Mendonca P (2007) Non-structural adobe walls in housing building - environmental performance. Proceedings of the International Symposium on Earthen Structures. Interline Publishing, Bangalore, India.

Minke G (2000) Earth Construction Handbook: The Building Material Earth in Modern Architecture. WIT Press, Southampton, UK.

Mortenson N (2000) The Naturally Air Conditioned House, latest update. See http://www.dab.uts.edu.au/ebrf/research/ air_conditioned.html (accessed 08/04/2010).

Oreszczyn T, Ridley I, Hong SH, Wilkinson P and Warm Front Study Group (2006) Mould and winter indoor relative humidity in low income households in England. Indoor and Built Environment 15(2): 125-135.

Osanyintola OF and Simonson CJ (2006) Moisture buffering capacity of hygroscopic building materials: experimental facilities and energy impact. Energy and Buildings 38(10): $1270-1282$.

Padfield T (1998) The Role of Porous Building Materials in Moderating Changes of Relative Humidity. Technical University of Denmark, Kongens Lyngby, Denmark. Rode C (2005) Moisture Buffering of Building Materials. Technical University of Denmark, Kongens Lyngby, Denmark, BYG DTU R-126.

Simonson CJ, Salonvaara M and Ojanen T (2002) The effect of structures on indoor humidity - possibility to improve comfort and perceived air quality. Indoor Air 12(4): 243251.

Taylor P and Luther MB (2004) Evaluating rammed earth walls: a case study. Solar Energy 76(1-3): 79-84.

\section{WHAT DO YOU THINK?}

To discuss this paper, please email up to 500 words to the editor at journals@ice.org.uk. Your contribution will be forwarded to the author(s) for a reply and, if considered appropriate by the editorial panel, will be published as discussion in a future issue of the journal.

Proceedings journals rely entirely on contributions sent in by civil engineering professionals, academics and students. Papers should be 2000-5000 words long (briefing papers should be 1000-2000 words long), with adequate illustrations and references. You can submit your paper online via www.icevirtuallibrary.com/content/journals, where you will also find detailed author guidelines. 